
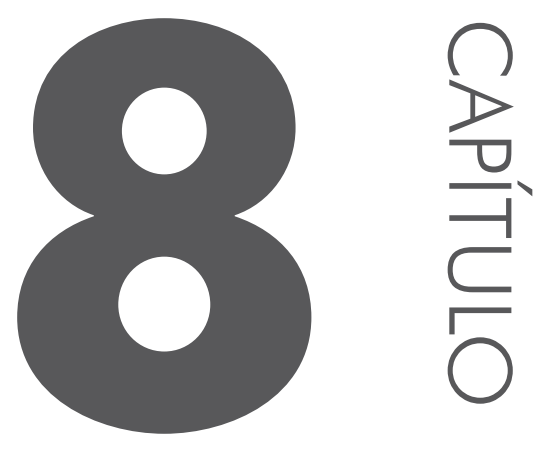

\title{
A VARIÁVEL SEXO/GÊNERO E O USO DE MARCADORES DISCURSIVOS NO OESTE DE SANTA CATARINA
}

\author{
Cláudia Andrea Rost Snichelotto \\ André Fabiano Bertozzo
}

\section{INTRODUC̣ÃO}

Neste trabalho, discutimos padrões de comportamento da variável sexo/gênero a partir do exame de estudos cujo foco são itens de natureza discursiva, notadamente Marcadores Discursivos (MD) originários de verbos (olha e vê, sabe? e entende?, eu acho, sei lá, deixa eu ver, deixa eu 
pensar e deixa eu lembrar), com base em entrevistas de duas amostras de fala de informantes de Chapecó/SC: uma do projeto VARSUL e a outra do projeto "Variação e Mudança no Português do Oeste de Santa Catarina" (VMPOSC) ${ }^{1}$.

Oriundos de categorias gramaticais diversas (conjunções, preposições, advérbios, verbos, adjetivos, etc.) e de estruturas sintáticas distintas, os MD abarcam uma ampla gama de itens lexicais e de sons não lexicalizados $(u h n, u b n u h n)$. "Isto significa que não é pela classe gramatical que identificamos os MC, mas pela função que aquela forma tem na interação." (MARCUSCHI, 1989, p. 290). Portanto, é comum a literatura considerálos como uma classe funcional (SCHIFFRIN, 1987; RISSO; SILVA; URBANO, 1996, 2006), tendo em vista a articulação simultânea de diferentes valores, com graus de maior ou menor proeminência, tanto de caráter textual - estabelecendo elos coesivos entre partes do texto, como interpessoal, mantendo a interação falante-ouvinte e auxiliando no planejamento da fala (MARCUSCHI, 1989).

Essa definição realça a função pragmática da categoria, na qual se pode também incluir a subclasse de MD derivados de verbos de percepção (visual, gustativa e olfativa) e de cognição: olha e vê, sabe? e entende?, eu acho, sei lá, deixa eu ver, deixa eu pensar e deixa eu lembrar.

Embora variados estudos (SILVA; MACEDO, 1996; CASTILHO, 1989; RISSO, 1999; URBANO, 1999; DAL MAGO, 2001; ROST, 2002, FREITAG, 2008, entre outros) tenham descrito e sistematizado os usos e valores dos MD no Português Brasileiro, Freitag (2007) observa que as gramáticas prescritivas (por exemplo, de CUNHA; CINTRA, 2001; LUFT, 1991) ainda os rotulam como "vício de linguagem" ou "cacoete linguístico”. Consequentemente, são estigmatizados, não só pelo ensino regular mas também pelos cursos de formação continuada, como os de (re)colocação no mercado de trabalho, especialmente para profissionais que atuam em áreas que requerem relacionamento ou fala em público. Ainda que os contextos escolar e profissional insistam nas atitudes e nos juízos de alta virulência, os $\mathrm{MD}$, altamente frequentes na fala, já começam a surgir na escrita, como evidenciaram Dal Mago (2002) e Freitag (2007).

Quanto a padrões de comportamento social construídos historicamente, alguns estudos conjecturam que as mulheres tenderiam ao maior emprego de MD devido a, em nossa sociedade patriarcal, se mostrarem mais polidas ao se comunicarem (SILVA; MACEDO, 1989). Porém, esse argumento pode ser questionado na perspectiva de Brown e Levinson

1 Este projeto foi financiado com recursos da Chamada Pública FAPESC n ${ }^{\circ}$ 04/2012 Universal e aprovado pelo Comitê de Ética em Pesquisa da Universidade Federal da Fronteira Sul (Processo CAAE: 17011413.2.0000.5564). 
(2002[1987]), para quem a necessidade de ser polido depende fundamentalmente das relações face a face. Os resultados de Silva e Macedo (1989) e Rost (2002) apontam que as mulheres fazem maior uso dos MD do que os homens. Tais premissas sugerem a necessidade de maior investigação dos efeitos da variável sexo/gênero no comportamento destes fenômenos.

\subsection{O EFEITO DA VARIÁVEL SEXO/GÊNERO EM FENÔMENOS DISCURSIVOS}

A influência do fator sexo/gênero sobre o uso de fenômenos discursivos aponta para comportamentos bastante diferenciados. Silva e Macedo (1989, p.15), por exemplo, analisando dados da amostra Censo do Rio de Janeiro, verificaram que as mulheres tenderam ao maior emprego de MD "iniciadores de respostas", como olha, bom e ah (SILVA; MACEDO, 1989, p.40). Porém, não houve diferença na frequência de uso dos Requisitos de Apoio Discursivo (RAD), como sabe?, entendeu?, né? entre os informantes do sexo masculino e os do sexo feminino.

Valle (2001) verificou comportamento semelhante entre os informantes masculinos e femininos em dados da amostra do Varsul/Florianópolis, porém atestou que há RADs de uso preferencial pelos homens - não tem? e entende? - e pelas mulheres - sabe?

O estudo de Rost (2002) também evidenciou preferências de uso dos MDs derivados dos verbos de percepção visual "olhar" e "ver", ao comparar amostras orais do Varsul provenientes das três capitais da Região Sul. Tomados como variantes da variável discursiva, olha e $v \hat{e}^{2}$ atuam no domínio funcional da "chamada da atenção do ouvinte". Os resultados da pesquisa revelaram que informantes femininos tenderam ao emprego do MD olha em oposição aos informantes masculinos que optaram pelo uso de $v \hat{e}$. Em termos de frequência, as mulheres usam um pouco mais os marcadores olha e veja do que os homens.

Os resultados desses três estudos no português evidenciam comportamentos diferenciados quanto ao gênero/sexo dos informantes e o uso dos $\mathrm{MD}$, na medida que a categoria não é uniforme, apresentando especificidades. Quanto à função RAD, os informantes de ambos gêneros/sexos empregam-nos de modo similar. Já na função de MD iniciadores de resposta (olha, bom e ah) ou os de chamada da atenção do ouvinte (olha e vêe), as informantes utilizam-nos mais em relação aos informantes.

Saindo do âmbito dos estudos do português brasileiro, Macaulay

2 A forma olha recobre as realizações olha ['oja $\sim$ ['oj] $\sim$ ['o] olhe. A forma vê representa as realizações vê $\sim v \hat{e} s \sim v e j a$. 
(2002) sumariza resultados de quatro pesquisas que focalizam o comportamento de fenômenos discursivos por gênero/sexo nas diferentes variedades do inglês.

Dubois e Crouch (1975), citados por Macaulay (2002, p. 294), investigaram o uso de tag questions durante as seções de discussão após a apresentação de trabalhos em workshops e constataram que homens empregaram-nas de modo mais intenso do que as mulheres. Inversamente, Holmes (1984, 1995), também referido por Macaulay (2002, p. 294), servindo-se de uma amostra de fala de homens e mulheres da Nova Zelândia, localizou maior uso de tag questions por mulheres do que por homens. Macaulay (2002, p. 295) também refere à pesquisa de Cameron et al. (1989), que encontraram resultado semelhante a Dubois e Crouch (1975) com preponderância de emprego de tag questions por homens em relação às mulheres.

Analisando dados de fala de informantes do corpus London-Lund, Erman (1993), mencionado por Macaulay (2002, p. 295, grifo nosso), demonstrou que "expressões pragmáticas", oriundas de formas verbais como you know, you see e I mean, são mais empregadas pelos homens do que pelas mulheres e também dispõem de funções discursivas distintas para ambos os sexos. Enquanto os homens preferem empregar estas construções como mecanismos para testar a atenção do interlocutor, as mulheres usam-nas para conectar argumentos consecutivos.

Se no português do Brasil há certa preferência de uso de MD pelas mulheres em relação aos homens, no inglês, observa-se o contrário, com os homens tomando a frente das mulheres quando se trata do emprego de tag questions e de expressões pragmáticas. Tal resultado contrastivo evidencia o quão complexa é a questão do sexo/gênero e como não podemos nos ater a hipóteses universais para o seu comportamento.

\subsection{PROCEDIMENTOS METODOLÓGICOS}

A metodologia dos estudos aqui sumarizados seguiu os passos da sociolinguística quantitativa laboviana, embora não sejam estudos puramente variacionistas, mas apenas de caráter exploratório. São duas as amostras orais utilizadas pelas pesquisas. A amostra do projeto VARSUL/Chapecó é constituída por entrevistas sociolinguísticas de 24 informantes chapecoenses, coletadas no início da década de 90 do século XX. Os informantes estão socialmente estratificados quanto às variáveis idade (de 25 a 49 e acima de 50 anos), escolaridade (antigos primário, ginasial e colegial) e sexo (masculino e feminino). As entrevistas de Chapecó foram realizadas por entrevistadoras femininas, de escolaridade superior, aparentemente de 
fora da região. A amostra do projeto VMPOSC é composta por 12 entrevistas sociolinguísticas de informantes de Chapecó, monolíngues em português, socialmente estratificados em sexo/gênero (masculino e feminino), idade ( 7 a 14 anos e 25 a 49 anos) e escolaridade $\left(1^{\circ}\right.$ e $2^{\circ}$ ciclos do ensino fundamental e ensino superior). Esta segunda amostra, de certo modo, pretende ser uma ampliação do VARSUL/Chapecó com a inserção de perfis socioculturais não contemplados à época de coleta das primeiras entrevistas do projeto. Além disso, as entrevistas foram efetuadas em 2014 por entrevistadores masculinos e femininos, de escolaridade superior, nascidos em Chapecó ou região. Em cada célula, uma entrevista foi feita por um homem e a outra por uma mulher. Com esse cuidado, este projeto enquadra-se à terceira onda dos estudos sociolinguísticos (ECKERT, 2005, 2012), tendo em vista a ênfase às questões estilísticas envolvidas no controle da coleta das entrevistas (ROST SNICHELOTTO, 2012).

Dos quatro trabalhos, um (ROST SNICHELOTTO, 2009) utilizou a amostra do projeto VARSUL e os outros três (TRAPP, 2014; SILVA, 2014; SCHERER, 2014) tomaram ambas as amostras orais disponíveis em Chapecó. A restrição espaço-temporal permite identificar tendências que podem ser relacionadas a questões de identidade local, na medida que, como vimos, o padrão de comportamento da macrocategoria dos MD varia muito.

Devido à baixa recorrência do fenômeno, e da restrição da amostra (e, consequentemente, de dados levantados), o viés de análise dos estudos é o funcionalismo linguístico, traçando os possíveis caminhos e a mudança de estatuto categorial dos MD analisados. No entanto, variáveis sociais inerentes à estratificação sociolinguística, como sexo/gênero e a faixa etária do informante, foram controladas, e é nesses resultados que focamos a seguir.

\subsection{TENDÊNCIAS DE USO DOS MD QUANTO AO SEXO/GÊNE- RO EM CHAPECÓ}

Os quatro estudos aqui sumarizados partiram de pesquisas anteriores que investigaram a mudança semântico-pragmática dos verbos para delinear a origem e potencialidade semântico-pragmática de cada item, desde sua base verbal como item lexical pleno até seu comportamento como MD.

Rost Snichelotto (2009) constatou que olha e vê (e suas variações) ${ }^{3}$, oriundos de verbos de percepção visual associados a segunda pessoa do

3 As formas olha e vê apresentam realizações distintas: a primeira é recoberta pelos usos de olha olhe $\sim$ ['oja $] \sim\left[{ }^{\circ} \mathrm{oj}\right] \sim\left[{ }^{\circ} \mathrm{o}\right]$ e a segunda, vejas $\sim$ veja $\sim$ vê $\sim$ vês. 
singular em enunciados de comando na forma imperativa, possuem a propriedade comum de chamada da atenção do ouvinte. Tanto no português como em outras línguas românicas esses itens tendem a derivar MD, a exemplo do espanhol, francês, italiano, catalão e galego. No português brasileiro, esses MDs (e variações) foram investigados por Castilho (1989), Marcuschi (1989), Silva e Macedo (1996), Risso, Silva e Urbano (1996), Martelotta, Votre e Cezario (1996), Urbano (1999), Risso (1999), Travaglia (1999) e Rost (2002).

Também fixados na segunda pessoa do singular, mas do presente do indicativo, os MD sabe? e entende? (e variações), segundo Trapp (2014), atuam no domínio funcional da manutenção do contato discursivo, a partir do qual, a depender do contexto, coexistem como camadas, nos termos de Hopper (1991), ou como variantes da mesma variável, nos termos de Labov (1978). No português brasileiro, outras pesquisas acerca desse subgrupo de MD foram efetuadas por Marcuschi (1989), Silva e Macedo (1996), Urbano (1997, 1999, 2006), Martelotta e Leitão (1996), Valle (2001), Martelotta (2004) e Görski e Valle (2013).

Silva (2014) verificou que sei lá e eu acho, cristalizados na primeira pessoa do singular do presente do indicativo, atuam como MD oracionais parentéticos epistêmicos ${ }^{4}$ e situam-se sob o domínio funcional da modalização epistêmica. Foram localizados estudos anteriores sobre esses MD (e variações) em Rosa (1992), Galembeck e Carvalho (1997), Freitag (2000, 2003, 2004), Votre (2004), Oliveira e Santos (2011).

Os usos dos MDs deixa eu ver, deixa eu pensar e deixa eu lembrar (e variações), de feição oracional, foram descritos por Scherer (2014) com base em estudos prévios realizados por Cezário, Gomes e Pinto (1996), Bagno (2001), Martins e Lacerda (2013) e Alves (2006). O verbo causativo deixar, usado no imperativo afirmativo, acompanhado de verbos de percepção e cognição, no infinitivo, está enfraquecendo ou perdendo características de verbos plenos de origem e se especializando como MDs.

$\mathrm{Na}$ sequência, passamos a apresentar o comportamento da variável gênero/sexo a partir do exame de análises efetuadas em cada um dos estudos. Ressaltamos ainda que foi possível a exposição de resultados da correlação entre as variáveis faixa etária e gênero/sexo das quatro pesquisas a fim de postularmos possíveis indícios de mudança em curso.

4 Compreende-se como "parentético" a forma sintaticamente isolada dos itens e "epistêmico" diz respeito à função de modalização proeminente no contexto em que a forma ocorre. 


\subsubsection{Marcadores discursivos olha e vê}

Rost Snichelotto (2009) descreveu a multifuncionalidade de usos dos MD olha e vê na fala e na escrita catarinense. Os dados de fala são oriundos de amostras do Varsul das cidades de Florianópolis, Lages, Blumenau e Chapecó. Esses itens apresentam caráter bidirecional, pois, além de chamar a atenção do interlocutor para a informação veiculada, auxiliam no estabelecimento de relações coesivas. Foram identificados dez contextos de atuação discursiva de olha e vê nas amostras analisadas: de advertência, adversativo, de atenuação, interjetivo, de prefaciação, de parentetização, exemplificativo, de opinião, causal e concessivo. Desses dez contextos mapeados, olha e vê competem em oito contextos. Portanto, em apenas dois contextos, ocorre uso exclusivo do MD olha (de atenuação e concessivo). Nesse caso, podemos interpretar esses contextos, pelo menos nas amostras analisadas, como de restrição ao uso de $v \hat{e}$.

A sequência de trechos a seguir mostra usos dos MD olha e de vê na fala de informantes chapecoenses:

Entrevistadora: É, e o que é que o senhor gosta mais de ver na televisão?

Informante: Olha, quer dizer, tem muitos homens que não gostam, mas aquilo que eu gosto de ver, por exemplo, essas novelas de como eu, quer dizer, que não perdia nenhum o Pantanal. (SC CHP 14)

Entrevistadora: [Conta] um pouco porque eu não conheço nada, eu tenho muita curiosidade porque [é] tem o aeroporto, tem a praça, [muita coisa]

Informante: [Doutor Serafim,] esse é filho do falecido Ernesto Bertaso, né? [esse] [esse foi] ele foi colonizador daqui. [Então ele vendia] o meu pai ia vender terras pra ele, né? Ele tinha terras por toda parte aqui, colônias, e o pai ia fazer as vendas pra ele. E era uma gente assim muito boa, gente que tinha. E ele tinha só três filhos: o Doutor Serafim, o Doutor Jaime [e a Dona] e a Dona Elza. Vive só a Dona Elza hoje, os outros já morreram, ele morreu, a Dona Zenaide morreu, com cento e seis anos, a esposa do seu Bertaso. É, agora esse ali, então, [o Doutor Serafim que é] o Doutor, como é o nome dele, que é filho do Doutor Serafim. Ai, meu Deus! Vêe, como a gente esquece Ivan Bertaso, casado com a Eliane que é uma senhora, a Eliane Silvestre. Só esses ali, [<el>] eles têm duas filhas, mas não moram mais aqui não. Não sei onde estão morando. Ele 
foi um grande colonizador daqui, comprava terras depois vendia, e o pai fazia as vendas pra ele, até lá pro Quilombo, Xaxim, lá pra Mondaí, Pinhalzinho, por aí tudo o pai ia vender as terras. (SC CHP 21)

Os resultados da amostra do Varsul/Chapecó indicam diferença percentual significativa nessa comunidade. Os homens tendem ao emprego do MD olha (116 ocorrências) em relação às mulheres (58 ocorrências). Esses resultados para o MD olha diferenciam-se dos apontados por Silva e Macedo (1989) e Rost (2002).

Vejamos, na tabela 1 , os resultados da correlação entre as variáveis faixa etária e gênero/sexo.

\section{Tabela 1: Correlação entre as variáveis faixa etária e gênero/sexo sobre 0 uso de olha em relação vê na amostra do Varsul/Chapecó. Adaptada de Rost Snichelotto (2009, p. 408)}

\begin{tabular}{c|c|c}
\hline Faixa etária & Masc./Varsul & Fem./Varsul \\
\hline A (25 a 49 anos) & $63 / 69(91 \%)$ & $25 / 37(68 \%)$ \\
B (50 anos ou +) & $38 / 47(81 \%)$ & $18 / 21(86 \%)$ \\
Total & $101 / 116(87 \%)$ & $43 / 58(74 \%)$ \\
\hline
\end{tabular}

A correlação entre idade e gênero/sexo dos informantes da amostra VARSUL/Chapecó é indicativa da diferenciação de uso dos MD. O MD olha predomina em relação a vê entre os informantes chapecoenses. Mesmo assim, são os homens das faixas A e B e as mulheres da faixa B que apresentaram os maiores percentuais de emprego de olha. Embora as mulheres de ambas as faixas etárias apresentem menor frequência de MD, isto é, exatamente $50 \%$ (58 ocorrências) do total de dados dos homens, ainda assim houve predomínio de olha entre os informantes femininos. Destaca-se, porém, que dos 24 informantes da amostra VARSUL/Chapecó apenas três homens da faixa etária $\mathrm{B}$ não produziram nenhum dos itens investigados. Houve equilíbrio (15 ocorrências cada) na realização do MD $v \hat{e}$ entre os sexos/gêneros, dentre os quais 6 dados foram identificados entre homens da faixa A e 11 entre os da faixa B, ao passo que ocorreu 12 realizações de $v \hat{e}$ entre as mulheres da faixa $\mathrm{A}$ e 3 entre as da faixa $\mathrm{B}$.

Em síntese, o sexo/gênero masculino é favorecedor do MD olha, mas desfavorecedor do MD vê em Chapecó. Apesar da baixa ocorrência dos $\mathrm{MD}$, o gênero/sexo feminino também mostra-se mais propício ao uso do MD olha em Chapecó. Esses resultados vão parcialmente ao encontro dos de Silva e Macedo (1989) e Rost (2002) que apontam a tendência de maior emprego dos MD entre as mulheres do que entre os homens.

Quanto às faixas etárias, o aparecimento (quase) categórico do MD 
olha pode indicar um contexto de especialização de uso entre os informantes masculinos mais jovens, enquanto que os informantes femininos da mesma faixa de idade revelaram preferência pelo uso de olha mas também alguns contextos de variação com vê. Nesse caso, podemos projetar uma possibilidade de entrada dos MD vê entre as mulheres chapecoenses mais jovens, porém os resultados significativamente altos da faixa mais velha não abonam a hipótese de alguma tendência em curso.

\subsubsection{Marcadores discursivos sabe? e entende?}

Trapp (2014) descreveu os contextos de uso dos MD sabe? e entende? na fala de 36 informantes do município de Chapecó, Santa Catarina. Além de 12 entrevistas do projeto VMPOSC, a autora investigou 24 entrevistas de informantes do projeto VARSUL/Chapecó. Com o objetivo de verificar os contextos específicos em que os verbos saber e entender aparecem na sua forma mais abstrata, Trapp (2014) identificou, nas amostras, atuação bidirecional de sabe? e entende?, ou seja, a depender do contexto de uso, podem se sobressair nuanças mais voltadas à interação ou mais voltadas ao texto, as quais distribuem-se em cinco contextos: de reformulação, de opinião, de especificação, causal/conclusivo e de contraste.

Usos dos MD na fala dos informantes de Chapecó podem ser conferidos nos excertos a seguir:

Entrevistadora: E qual o trabalho dele, lá?

Informante: É, ele é mais a parte de cortar, tirar carne, assim, dos ossos, sabe? desossar, que dizem. (est) Então, [na]- [na]- desossar, tirar juntas, né? assim, da- Tira a carne, depois, daí, na junta, assim, daí corta tudo fora, né? (SC CHP 01)

(4)

Entrevistadora: E como é que é na tua casa Mari, essa questão de italianos, você fala italiano?

Informante: [...] E [eu]- eu sinto que na minha família ainda isso tá bem enraizado, entende? (est) o italiano porque a gente dá muito valor. (est) Tanto meu irmão, tenho um irmão que estuda fora, ele quer ver se ele se naturaliza italiano. (SC CHP 19)

No rastreamento da amostra VARSUL/Chapecó, Trapp (2014) localizou 135 ocorrências dos MD investigados, dentre as quais 118 ocorrências foram produzidas por mulheres e 17 por homens. Das 118 ocorrências produzidas pelas mulheres da amostra, $85 \%$ são realizações de sabe? (100 
ocorrências) e $15 \%$ de entende? (18 ocorrências). No que refere as 17 ocorrências produzidas por homens, deste total, $88 \%$ foram ocorrências de sabe? (15 dados) e $12 \%$ de entende? ( 2 dados). De modo geral, os resultados obtidos indicam que, embora apenas 14 informantes femininas tenham produzido os MDs sabe? e entende?, elas são responsáveis por $87 \%$ (118/135) das realizações da amostra do Varsul/Chapecó. De modo específico, os homens e as mulheres da amostra são mais produtivos do MD sabe?, com $85 \%$ e $88 \%$ de frequência, respectivamente.

No levantamento de dados da amostra do projeto VMPOSC, foram identificadas 11 ocorrências dos MDs investigados, destas, 5 são realizações produzidas por informantes mulheres e 6 por informantes homens. Como ocorreu com os resultados da amostra do Varsul/Chapecó, sabe? foi igualmente produtivo entre homens e mulheres (média de 5 ocorrências), ao passo que entende? foi produzido por apenas um informante masculino.

Vejamos, na Tabela 2, os resultados da correlação entre as variáveis faixa etária e gênero/sexo.

Tabela 2: Correlação entre as variáveis faixa etária e gênero/sexo sobre o uso de sabe? em relação entende? nas amostras de Chapecó dos projetos VARSUL e VMPOSC. Adaptado de Trapp $(2014$, p. 115, 117)

\begin{tabular}{c|cccc}
\hline \multirow{2}{*}{ Faixa etária } & \multicolumn{4}{|c}{ Gênero/sexo } \\
\cline { 2 - 5 } & Masc./Varsul & Fem./Varsul & Masc./VMPOSC & Fem./VMPOSC \\
\hline A (25 a 49 anos) & $09 / 09(100 \%)$ & $28 / 46(61 \%)$ & $05 / 06(83 \%)$ & $02 / 02(100 \%)$ \\
B (50 anos ou +) & $06 / 08(75 \%)$ & $72 / 72(100 \%)$ & - & - \\
C (7 a 14 anos) & - & - & - & $03 / 03(100 \%)$ \\
\hline
\end{tabular}

Atentando-se para os resultados da amostra VARSUL/Chapecó, a correlação entre idade e gênero/sexo dos informantes é indicativa da diferenciação de uso dos MDs. As mulheres da faixa etária B usam exclusivamente o MD sabe? (72 ocorrências) em comparação às mulheres da faixa $\mathrm{A}$, que apresentaram emprego variável de ambos MDs (28 ocorrências de sabe? e 18 de entende?). Embora os homens de ambas as faixas etárias apresentem baixa frequência (17 dados apenas) de uso de ambos os MDs em relação às mulheres, houve predomínio de sabe? entre os homens da faixa etária A. Contudo, foram os homens da faixa etária B que variaram o emprego dos MDs (6 ocorrências de sabe? e 2 de entende?).

Com a entrada dos universitários da amostra do VMPOSC, verifica-se o inverso: os informantes masculinos da faixa A apresentaram emprego variável de ambos MDs (5 ocorrências de sabe? e 1 de entende?), e os infor- 
mantes femininos dessa mesma faixa etária apresentaram uso preferencial de sabe? (2 ocorrências). Também este é o uso preferencial dos informantes femininos da faixa mais jovem.

Os resultados de ambas as amostras com entrevistas de informantes chapecoenses divergem dos de Silva e Macedo (1989) e Valle (2001), uma vez que houve diferença de uso entre os informantes do sexo masculino e os do sexo feminino.

\subsubsection{Marcadores discursivos sei lá e eu acho}

Silva (2014) analisou os usos dos MD sei lá e eu acho na fala de 32 chapecoenses, com base em duas amostras sincrônicas, uma proveniente do projeto VARSUL/Chapecó, com 24 entrevistas, e outra do projeto VMPOSC, que contava à época da redação da dissertação com 8 entrevistas coletadas.

A atuação desses MD na fala de informantes de Chapecó pode ser conferida nas ocorrências a seguir:

Entrevistador: Tinha igreja já ou não?

Informante: Tinha. Só que era uma igreja de- não era essa igreja, uma igreja que foi queimada depois. Não sei o que que aconteceu ali, dizem que botaram fogo, sei lá (SC CHP 02)

(6)

Informante: Ele foi me dar uma moeda de esmola, né? Ele disse:

"Eu vou te dar essa." Eram quatrocentos réis, eu acho. ${ }^{\text {(SC CHP 20) }}$

Em seu levantamento de dados do VARSUL/Chapecó, Silva (2014) verificou que, das 18 entrevistas em que foram identificados os MDs investigados, 11 são de informantes mulheres e 7 são de informantes homens. Consequentemente, o maior uso de sei lá se dá entre as mulheres (60\%) em relação aos homens (40\%). Entre as mulheres foi maior o uso da forma sei lá $(93,3 \%)$, seguido pela forma sei lá eu $(6,7 \%)$. Os homens também preferiram o uso da forma sei lá (90\%), seguido de eu sei lá (10\%). Igualmente as mulheres apresentam taxas um pouco mais altas de uso de eu acho $(54,3 \%)$ do que homens $(45,7 \%)$. De modo específico, as mulheres preferem a forma eu acho (72\%), seguida da forma acho $(24 \%)$ e de acho eu $(4 \%)$. Os homens também preferem a forma eu acho $(61,9 \%)$, seguida de acho (28,6\%) e de acho eu (9,5\%).

No rastreamento de dados da amostra do projeto VMPOSC, foi possível verificar usos de sei lá exclusivos das mulheres e maior frequência de 
eu acho também entre os informantes do sexo/gênero feminino. Quanto a este último MD, de 8 ocorrências totais do item, apenas uma foi realizada por informante do sexo/gênero masculino, as demais foram realizações de informantes do sexo/gênero feminino.

Portanto, o que se configura quanto ao comportamento de sei lá e eu acho é um maior uso do primeiro por mulheres em ambas amostras investigadas e o emprego do segundo quase equivalente entre mulheres e homens na amostra VARSUL/Chapecó.

Vejamos, na Tabela 3, a seguir, os resultados da correlação entre a variável faixa etária e gênero/sexo.

Tabela 3: Correlação entre as variáveis faixa etária e gênero/sexo sobre o uso de sei lá em relação a eu sei lá e sei lá eu nas amostras de Chapecó dos projetos VARSUL e VMPOSC. Adaptada de Silva (2014, p. 95-96)

\begin{tabular}{c|cccc}
\hline \multirow{2}{*}{ Faixa etária } & \multicolumn{4}{|c}{ Gênero/sexo } \\
\cline { 2 - 5 } & Masc./Varsul & Fem./Varsul & Masc./VMPOSC & Fem./VMPOSC \\
\hline A (25 a 49 anos) & $18 / 40(45 \%)$ & $22 / 40(55 \%)$ & - & - \\
B (50 anos ou +) & $02 / 10(20 \%)$ & $08 / 10(80 \%)$ & - & - \\
C (7 a 14 anos) & - & - & $00 / 15(0 \%)$ & $15 / 15(100 \%)$ \\
\hline
\end{tabular}

Os resultados apresentados na Tabela 3 sinalizam que as mulheres das três faixas etárias, diferentemente dos homens, apresentam maior uso das formas dos itens investigados. Em termos percentuais, foi a faixa mais jovem (de 7 a 14 anos) das informantes mulheres que produziu mais a forma sei lá $(55 \%)$ em relação aos informantes homens, que sequer realizaram quaisquer das formas dos itens. O sexo/gênero feminino da faixa etária B também produziu mais a forma sei lá em comparação ao sexo/gênero masculino. 
Vejamos, na Tabela 4, a seguir, os resultados da correlação entre a variável faixa etária e gênero/sexo.

Tabela 4: Correlação entre as variáveis faixa etária e gênero/sexo sobre o uso de eu acho nas amostras de Chapecó dos projetos VARSUL e VMPOSC.

Adaptada de Silva (2014, p. 97-98)

\begin{tabular}{c|cccc}
\hline \multirow{2}{*}{ Faixa etária } & \multicolumn{4}{|c}{ Gênero/sexo } \\
\cline { 2 - 5 } & Masc./Varsul & Fem./Varsul & Masc./VMPOSC & Fem./VMPOSC \\
\hline A (25 a 49 anos) & $18 / 27(66,7 \%)$ & $09 / 27(33,3 \%)$ & - & - \\
B (50 anos ou +) & $03 / 19(15,8 \%)$ & $16 / 19(84,2 \%)$ & - & - \\
C (7 a 14 anos) & - & - & $01 / 08(12,5 \%)$ & $07 / 08(87,5 \%)$ \\
\hline
\end{tabular}

Os resultados apresentados na Tabela 4 ressaltam que a maior frequência de uso da forma eu acho se dá entre os homens da faixa etária A e entre as mulheres da faixa B e C. Em termos percentuais, foi a faixa mais jovem (de 7 a 14 anos) das informantes mulheres que produziu mais eu acho $(87,5 \%)$ em relação aos informantes homens, que realizaram apenas uma ocorrência dos itens. $\mathrm{O}$ sexo/gênero feminino da faixa etária $\mathrm{B}$ também produziu mais a forma $e u$ acho em comparação ao sexo/gênero masculino.

\subsubsection{Marcadores discursivos deixa eu ver, deixa eu pensar e deixa eu lembrar}

O estudo de Scherer (2014) tem como base de investigação duas amostras sincrônicas, sendo uma da cidade de Chapecó do projeto VMPOSC e outra das cidades de Chapecó, Blumenau, Lages e Florianópolis, do projeto VARSUL/Santa Catarina.

Usos, extraídos da amostra do Varsul/Chapecó, de deixa eu ver, deixa eu pensar e deixa eu lembrar como MD podem ser verificados no excerto a seguir:

Informante: - Era o meu bem que ela queria, né? Porque hoje ela até se arrepende do dia que ela falou, que ela adora a Rafaela. [E a] deixe eu ver o que mais. Faz uma pergunta pra mim. (SC CHP 20)

Entrevistador: - A senhora correu algum perigo de vida, alguma situação muito ruim, com a senhora, que tenha marcado?

Informante: - Deixa eu pensar um pouquinho. Ah, aquela do homem, aquele que se incomodou porque eu não aceitei a esmola 

dele, né,? E depois eu fiquei com medo. (SC CHP 21)

Informante: - Se bem que é tudo macete, né? Tem umas coisas que eu não posso dizer aqui. Deixa eu lembrar uma aqui que eu posso te dizer. É muito maroto aqueles ensaio lá.(SC CHP 18)

Nos dados levantados por Scherer (2014) na amostra do VARSUL, as mulheres apresentaram 17 ocorrências dos MD investigados enquanto que os homens, apenas 5. Especificamente em Chapecó, das 9 ocorrências localizadas, 3 foram produzidas por homens e 6 por mulheres. $\mathrm{Na}$ amostra do projeto VMPOSC, não há diferença de frequência de uso quanto ao sexo/gênero do informante, ou seja, houve duas ocorrências produzidas por homens e duas por mulheres.

De modo geral, embora relativizando a baixa frequência de MD nas amostras investigadas, observamos que o gênero/sexo feminino pode estar utilizando mais os MD em estudo do que os homens, pois todas as cidades da amostra VARSUL/SC apresentam ocorrências dos MD entre as mulheres.

Vejamos, na Tabela 5, os resultados da correlação entre a variável faixa etária e sexo/gênero.

Tabela 5: Correlação entre as variáveis faixa etária e gênero/sexo sobre o uso de deixa eu ver, deixa eu pensar e deixa eu lembrar nas amostras de Chapecó dos projetos VARSUL e VMPOSC. Adaptada de Scherer (2014, p. 114-116)

\begin{tabular}{c|cccc}
\hline \multirow{2}{*}{ Faixa etária } & \multicolumn{4}{|c}{ Gênero/sexo } \\
\cline { 2 - 5 } & Masc./Varsul & Fem./Varsul & Masc./VMPOSC & Fem./VMPOSC \\
\hline A (25 a 49 anos) & $3 / 6(50 \%)$ & $3 / 6(50 \%)$ & $1 / 1(100 \%)$ & $0 / 1(0 \%)$ \\
B (50 anos ou +) & $0 / 3(0 \%)$ & $3 / 3(100 \%)$ & - & - \\
C (7 a 14 anos) & - & - & $1 / 3(33 \%)$ & $2 / 3(67 \%)$ \\
\hline
\end{tabular}

Os resultados apresentados na Tabela 5, embora relativizados devido ao restrito número de ocorrências, ressaltam que a maior frequência de uso dos MD se dá entre as mulheres das três faixas etárias (8 ocorrências) em comparação aos homens (5 ocorrências). Em termos percentuais, foi a faixa etária $\mathrm{B}$ das informantes mulheres que apresentou uso exclusivo dos $\mathrm{MD}$ em relação aos informantes homens. Houve equilíbrio quanto ao uso dos itens entre o sexo/gênero feminino e masculino da faixa etária A.

\section{CONSIDERAC̣ÕES FINAIS}

Nosso objetivo neste texto foi fomentar a discussão de padrões de 
comportamento da variável sexo/gênero a partir do exame de análises efetuadas em estudos sobre MDs com base em entrevistas de duas amostras de fala de informantes de Chapecó/SC.

Resumidamente, em relação aos fenômenos discursivos aqui explorados, pode-se dizer que: (i) na amostra do VARSUL/Chapecó, os homens tendem ao emprego do $\mathrm{MD}$ olha em relação às mulheres; (ii) na amostra do VARSUL/Chapecó e do VMPOSC, sabe? foi igualmente produtivo entre homens e mulheres, ao passo que entende? foi menos produtivo; (iii) na amostra do VARSUL/Chapecó e do VMPOSC, o que se configura quanto ao comportamento de sei lá e eu acho é um maior uso do primeiro por mulheres e emprego do segundo quase equivalente entre mulheres e homens; (iv) na amostra do Varsul/Chapecó e do VMPOSC, embora relativizando a baixa frequência de MDs localizados, observamos que o sexo/ gênero feminino utiliza mais os MDs deixa eu ver, deixa eu pensar e deixa eu lembrar do que os homens.

Os resultados das pesquisas mostram tendências de comportamento linguístico do gênero/sexo dos informantes e o uso dos MD nas amostras de Chapecó bastante distintas: (i) as mulheres tendem ao maior uso de MD (sei lá, deixa eu ver, deixa eu pensar, deixa eu lembrar) em relação aos homens, o que vem ao encontro de nossa expectativa inicial, especialmente sustentada nos resultados dos estudos de Silva e Macedo (1989) e Rost (2002); (ii) os homens, por sua vez, são mais propícios ao emprego de olha em relação às mulheres, o que contraria nossa expectativa; (iii) os homens e as mulheres tendem ao mesmo comportamento linguístico no que tange ao uso dos MDs sabe? e entende? e eu acho. 


\section{REFERÊNCIAS}

ALVES, Jeferson da S. A expressão variável do imperativo nas tiras do "Menino Maluquinho”. Caderno Seminal Digital, v. 6, n 6, jul./dez. 2006. Rio de Janeiro: Dialogarts, 2006.

BAGNO, Marcos. Português ou Brasileiro? Um convite à pesquisa. São Paulo: Parábola Editorial, 2001.

BROWN, Penelope; LEVINSON, Stephen. Politeness: some universals in language use. Cambridge, Cambridge University Press, 1987.

CASTILHO, Ataliba T. de. Para o estudo das unidades discursivas no português falado. In: CASTILHO, Ataliba T. (Org.). Português culto falado no Brasil. Campinas: Ed. da Unicamp, 1989. p.249-279.

CEZÁRIO, Maria M.; GOMES, Rosa L. R.; PINTO, Deise C. de M. Integração entre cláusulas e gramaticalização. In: MARTELOTTA, Mário E.; VOTRE, Sebastião J.; CEZÁRIO, Maria M. Gramaticalização no português do Brasil: uma abordagem funcional. Rio de Janeiro: UFRJ - Grupo de Estudos Discurso e Gramática, 1996.

CUNHA, Celso; CINTRA, Lindley. Nova Gramática do Português Contemporâneo. Rio de Janeiro: Nova Fronteira, 2001.

DAL MAGO, Diane. Quer dizer: percurso de mudança via gramaticalização e discursivização. 2001. Dissertação (Mestrado em Linguística) - Programa de Pós Graduação em Linguística - Universidade Federal de Santa Catarina, Florianópolis, 2001.

DAL MAGO, Diane. Uma possível trajetória de mudança para o item lexical quer dizer. Working Papers em Linguística, UFSC, n. 6, 2002.

FREITAG, Raquel M. Ko. "Mudar para variar", "variar para mudar" - tratando da variação e mudança de acho (que) e parece (que) parentéticos epistêmicos na fala de Florianópolis. Fórum Lingüístico, Florianópolis, v. 4, n.1, jul.2004, p. 81-113.

FREITAG, Raquel M. Ko. Estratégias de modalização epistêmica na fala dos florianopolitanos: talvez VS. (eu) acho que. Anais do IV Encontro do CELSUL, 2000.

FREITAG, Raquel M. Ko. Gramaticalização e variação de acho (que) e parece (que) na fala de Florianópolis. 2003. Dissertação (Mestrado em Linguística) Programa de Pós-Graduação em Linguística - Universidade Federal de Santa Catarina, Florianópolis, 2003.

FREITAG, Raquel M. Ko. Marcadores discursivos interacionais na fala de Itabaiana/SE. Revista do GELNE, 10 (1), p. 21-32, 2008.

FREITAG, Raquel M. Ko. Marcadores discursivos não são vícios de linguagem. 
Interdisciplinar: revista de estudos de língua e literatura, v. 4, p. 22-43, 2007. GALEMBECK, Paulo de T.; CARVALHO, Kelly A. Os marcadores conversacionais na fala culta de São Paulo. Projeto NURC (Norma Linguística Urbana Culta de São Paulo) São Paulo, p. 830-848, 1997.

GÖRSKI, Edair M. VALLE, Carla R. M. Marcadores em competição no domínio funcional da "Requisição de Apoio Discursivo". In: CEZARIO, Maria M.; CUNHA, Maria A. F da (Orgs.). Linguística Centrada no Uso: uma homenagem a Mário Martelotta. Rio de Janeiro: Maud X/FAPERJ, 2013.

LABOV, William. Where does the linguistic variable stop? A response to Beatriz Lavandera. Sociolinguistic Working Paper, 44, 1978.

LUFT, Celso P. Moderna gramática brasileira. Porto Alegre: Globo, 1991.

MACAULAY, Ronald. Discourse variation. In: CHAMBERS, K. K.; TRUDGILL, P.; SCHILLING-ESTES, N. (Eds.). The handbook of language variation and change. Oxford: Blackwell, 2002. p. 283-305.

MARCUSCHI, Luiz Antônio. Marcadores conversacionais do português brasileiro: formas, posições e funções. In: CASTILHO, Ataliba Teixeira de (Org.). Português falado culto no Brasil. Campinas: UNICAMP, 1989, p. 281-322.

MARTELOTTA, Mario E. Operadores argumentativos e marcadores discursivos. In: VOTRE, Sebastião J.; CEZARIO, Maria M.; MARTELOTTA, Mário E. Gramaticalização. Rio de Janeiro: Faculdade de Letras UFRJ, 2004.

MARTELOTTA, Mario E.; LEITÃO, Márcio. Discursivização do verbo saber. In: MARTELOTTA, Mario E.; VOTRE, Sebastião J.; CEZARIO, Maria M. (Org.) Gramaticalização no português do Brasil: uma abordagem funcional. Rio de Janeiro: Tempo Brasileiro/UFRJ, 1996.

MARTELOTTA, Mário E.; VOTRE, Sebastião; CEZARIO, Maria M. (Org.). Gramaticalização no português do Brasil: uma abordagem funcional. Rio de Janeiro: Tempo Brasileiro, 1996.

MARTINS, Lauriê F.; LACERDA, Patrícia F. A. da C. Marcadores discursivos dos verbos de percepção visual "olhar" e "ver": uma análise a partir da Sociolinguística Variacionista. Cadernos de Estudos Linguísticos, 55.2, Campinas, jul./ dez. 2013.

OLIVEIRA, Mariangela R.de; SANTOS, Leonardo P. Padrões de uso da expressão sei lá no Português. Revista Signótica, Goiânia, v. 23, n. 2, p. 363-384, jul./ dez. 2011.

RISSO, Mercedes S. Aspectos textuais-interativos dos marcadores discursivos de abertura Bom, Bem, Olha, Ah, no português culto falado. In: NEVES, M. H. M. (Org.). Gramática do português falado. Campinas: Ed. da Unicamp, 1999. v.7.

RISSO, Mercedes S.; SILVA, Giselle M. de O.; URBANO, Hudinilson. Marcadores discursivos: traços definidores. In: $\mathrm{KOCH}$, I. G. V. (Org.). Gramática do 
português falado. Campinas: Ed. da Unicamp, 1996. v.4. p.21-94.

RISSO, Mercedes S.; SILVA, Giselle M. de O.; URBANO, Hudinilson. Traços definidores dos Marcadores Discursivos. In: JUBRAN, C. C. A. S.; KOCH, I. G. V. (Orgs.). Gramática do português culto falado no Brasil. Campinas: Editora da UNICAMP, 2006. V. 1 - Construção do texto falado, p. 403-425

ROSA, Margaret de M. Marcadores de atenuação. São Paulo: Contexto, 1992.

ROST SNICHELOTTO, Cláudia A. “Olha” e "vê": caminhos que se entrecruzam. 2009. 408 f. Tese (Doutorado em Linguística) - Programa de Pós-Graduação em Linguística - Universidade Federal de Santa Catarina, Florianópolis, 2009. ROST, Cláudia A. Olha e veja: multifuncionalidade e variação. 2002. 158 f. Dissertação (Mestrado em Linguística) - Programa de Pós Graduação em Linguística - Universidade Federal de Santa Catarina, Florianópolis, 2002.

SCHERER, Eliane. De verbo causativo a marcador discursivo em Santa Catarina. 2014. Dissertação (Mestrado em Linguística) - Programa de Pós-Graduação em Estudos Linguísticos - Universidade Federal da Fronteira Sul, Chapecó, 2014.

SCHIFFRIN, Deborah. Discourse markers. Cambridge: Cambridge University Press, 1987.

SILVA, Giselle M. de O; MACEDO, A. T. de. Análise sociolinguística de alguns marcadores conversacionais. In: MACEDO, A.; RONCARATI, C.; MOLLICA, M. (Orgs.).Variação e discurso. Rio de Janeiro: Tempo Brasileiro, 1996. p. 11-50. SILVA, Josiana A. da. Modalizadores epistêmicos na fala de Chapecó/SC. 2014. Dissertação (Mestrado em Linguística) - Programa de Pós-Graduação em Estudos Linguísticos - Universidade Federal da Fronteira Sul, Chapecó, 2014.

TRAPP, Kelly. Os marcadores discursivos sabe? e entende? na fala de informantes do município de Chapecó/SC. 2014. Dissertação (Mestrado em Linguística) Programa de Pós-Graduação em Estudos Linguísticos - Universidade Federal da Fronteira Sul, Chapecó, 2014.

TRAVAGLIA, Luiz C. O relevo no português falado: tipos e estratégias, processos e recursos. In: NEVES, M. H. M. Gramática do português falado: novos estudos. São Paulo: Humanitas, 1999. v.7. p.77-130.

URBANO, Hudinilson. Aspectos basicamente interacionais dos marcadores discursivos. In: NEVES, M. H. de M. (Org.). Gramática do Português Falado. São Paulo: Humanitas/FFLCH/USP; Campinas: Editora da Unicamp; v.1, 1999, p. 195-258.

URBANO, Hudinilson. Marcadores conversacionais. In: PRETI, Dino. (Org.). Análise de textos orais. 3. ed. São Paulo: Humanitas Publicações FFLCH/USP, 1997, p. 81-101.

URBANO, Hudinilson. Marcadores discursivos basicamente interacionais. In: JUBRAN, C. C. A. S.; KOCH, I. G. V. (Orgs.). Gramática do português culto 
falado no Brasil. Campinas: Editora da UNICAMP, 2006. v. 1 - Construção do texto falado, p. 497-527.

VALLE, Carla R. M Sabe? Não tem? Entende?: itens de origem verbal em variação como Requisitos de Apoio Discursivo. 2001. Dissertação (Mestrado em Linguística) - Programa de Pós Graduação em Linguística - Universidade Federal de Santa Catarina, Florianópolis, 2001.

VOTRE, Sebastião J. Integração sintática e semântica na complementação verbal. In: MARTELOTTA, Mário Eduardo; VOTRE, Sebastião Josué; CEZÁRIO, Maria Maura. Gramaticalização. Rio de Janeiro: Faculdade de Letras UFRJ, 2004. 
208 